American Journal of Applied Sciences 5 (10): 1291-1295, 2008

ISSN 1546-9239

(C) 2008 Science Publications

\title{
A Sectoral Efficiency Analysis of Malaysian Stock Exchange Under Structural Break
}

\author{
Chin Wen Cheong \\ Faculty of Information Technology \\ Multimedia University, 63100 Cyberjaya, Selangor, Malaysia
}

\begin{abstract}
We investigated the weak-form market efficiency of nine daily sectoral indices of Malaysian stock market between 1996 and 2006. The structural break unit root tests evidenced most of the price indices characterized by mean-reverting process that violated the random walk process. These empirical results were in sharp contrast with the traditional unit-root test which ignored the economic crisis and currency control. Our findings concluded that the Malaysian sectoral stock markets were weak-form inefficient (except the property index) under the structural change.
\end{abstract}

Keywords: structural break, market efficiency, stock market, unit root test, random walk.

\section{INTRODUCTION}

The early study by French economist Louis Bachelier ${ }^{[1]}$ suggested that the presence of random walk theory in the French commodity markets where the random nature of the stock prices is unforecastable. Paul Samuelson ${ }^{[2]}$ has conducted similar study of the RWH to financial markets and concluded that price changes must be unpredictable if they are properly anticipated by all the market participants. The randomness of price changes are the results of instantaneous responses from an enormous investors who seeking for greater wealth. Investors incorporated their available (even a tiny piece of information) information into the market price and caused rapid prices adjustment. As a result, these actions have eliminated the possible of profit opportunities in the financial markets. $\mathrm{Fama}^{[3]}$ summarized this concept into three categories according to the information efficiency degree namely the weak-from efficiency (history of prices/returns), semi-strong efficiency (publicly available information) and strong efficiency (private information) respectively. The weak-form efficient market hypothesis (EMH), which is our focus, stated that the current asset price is determine only by its historical prices (information set) of that particular asset. If stock price failed to reject the random walk hypothesis (RWH), this implies that the future returns are unpredictable by using information on past returns. On the other hand, if the stock prices is characterized by a mean reverting (trend stationary) process, then there is a tendency for the price level to return to its trend path. This suggested that the presence of predictable component based on the historical information.

Recent literatures ${ }^{[4-6]}$ of market efficiency analysis have paid strong attentions to the presence of structural break in the financial time series. In general, these literatures reported that by ignoring the presence of SBs may lead to model misspecification problem, spurious statistical inference and consequently, wrong conclusions may be used to explain the actual financial market behaviour. In this specific study, the implications of random walk hypothesis of nine sectoral Malaysian stock prices. Normally, the associated important events such as foreign exchange scheme (from fixed to float or vice-versa), fiscal policy (increase in government expenditure), monetary policy (injection of extra money supply), terrorism events, nature disasters, etc., may contribute to the shift in price, return and volatility series.

In this paper, we have selected the Kuala Lumpur stock exchange (KLSE) as our case study. As one of the emerging market, the KLSE has received great attentions ${ }^{[7-10]}$ from researchers and investors as the testing ground for EMH, and potential investment alternatives. Firstly, we run the unit root test without the structural break to understand the time series properties of each of the selected stock market index. Later, we adopted the Zivot and Andrews ${ }^{[1]}$ test with the possible structural change in intercept and trend respectively. The inclusion of structural change in the unit root test which allowed for both the mean shift and trend shift are important to improve the econometrics tests reliability and consequently, improved the accurate statistical inference upon the market efficiency hypothesis.

Corresponding Author: Chin Wen Cheong, Faculty of Information Technology, Multimedia University, 63100 Cyberjaya, Selangor, Malaysia. Tel: +603-83125249, Fax: +603-83125264 
Data Source: In this study, we have selected the index prices (DATASTREAM) from $1^{\text {st }}$ August 1996 to $1^{\text {st }}$ $30^{\text {th }}$ June 2006 (2578 observations) which included the Asian crisis. During the Asian Financial crisis, the Malaysian stock market has experienced a massive slid due to the major factor of drastic depreciation of Malaysian Ringgit(RM) where the RM(RM2.50 in first half of 1997) was depreciated to the weakest rate recorded against USD as RM4.88 on $9^{\text {th }}$ January, 1988. Malaysian government had implemented the one USD pegged to RM3.80 in the $1^{\text {st }}$ September 1998 to stabilize the RM from currency speculation. After the implementation, the Malaysian economics show significant recovery. Firstly, we intended to identify the specific date for the possible structural change during the Asian crisis. Secondly, by including the presence of structural break, we test the underlying process for all the selected indices. The daily price series, $P_{t}$ is defined as the closed price on a trading day and the natural $\log$ of price is written in the form of : $p_{t}=\ln \left(P_{t, \text { close }}\right)$

\section{METHODOLOGY}

Andrews (1993) unknown break-point test: Andrews ${ }^{[12]}$ extended Quandt ${ }^{[13]}$ test by deriving the asymptotic distribution of the LR-like test for one shift based on first order autoregressive model:

$p_{t}=\rho_{\mathrm{I}} p_{t-1}+\varepsilon_{l t}, \quad t=1, \ldots, m$.

$p_{t}=\rho_{\text {II }} p_{t-1}+\varepsilon_{I I t}$,

$$
t=m+1, \ldots, \mathrm{T} \text {. }
$$

where $\varepsilon_{t} \sim N\left(0, \sigma_{t}^{2}\right)$. We allowed the OLS estimations under the possibility of heteroscedasticity. The estimated parameters remain unchanged but not the estimated standard errors. According to White ${ }^{[14]}$, the covariance matrix in a general case is given by:

$\operatorname{var}(\hat{\rho})=\left(p^{\prime} p\right)^{-1}\left(\sum_{t=1}^{\tau} \hat{\varepsilon}_{t}^{2} p_{t} p_{t}{ }^{\prime}\right)\left(p^{\prime} p\right)^{-1}$

where the square roots of the diagonal components are White standard errors. Andrews performed a single Chow test at every observations between $t=1, \ldots, \mathrm{T}$ and the maximum Chow's F-statistics is selected as the most possible location of structural change as follow:

$\operatorname{Sup} \mathbf{L R}-\mathbf{F}=\max _{1 \leq t \leq T} \frac{\left(\hat{\varepsilon}^{\prime} \hat{\varepsilon}-\left(\hat{\varepsilon}_{I}^{\prime} \hat{\varepsilon}_{I}+\hat{\varepsilon}_{I I}^{\prime} \hat{\varepsilon}_{I I}\right)\right) / k}{\left(\hat{\varepsilon}_{I}^{\prime} \hat{\varepsilon}_{I}+\hat{\varepsilon}_{I I}^{\prime} \hat{\varepsilon}_{I I}\right) /(T-2 k)}$
To avoid the distribution degeneration of these statistics, it is customary trimmed out the $7.5 \%$ for the first and last of the overall observations. Andrews suggested $15 \%$ of trimming to obtain a reliable statistical inference. However, the trimming may vary depended to the sample size accordingly. Thus, be more precise, the null hypothesis indicated no breakpoints within the trimmed observations. The details of the numerical approximations of these asymptotic distributions p-values can be found in Hansen ${ }^{[15]}$ where $p$-values are more preferable than the predefined significance tests.

The Zivot-Andrews test: The well-known unit root test such as Dickey Fuller ${ }^{[16]}$ and Phillips and Perron ${ }^{[17]}$ have low power and even spurious rejection of unit root caused by the presence of structural changes. ZivotAndrews test is proven ${ }^{[18-19]}$ outperformed in its power as compare to traditional test. The one-time shift in the intercept and trend under the structural break can be examined using the following equation:

$$
\begin{aligned}
\Delta p_{t}=\theta_{0}+\theta_{1} D M_{t}+\theta_{2} t+\theta_{3} D T_{t}+\delta p_{t-1}+\sum_{i=1}^{L} \pi_{i} \Delta p_{t-n}+\varepsilon_{t} \\
\text { where the } \mathrm{DM}_{\mathrm{t}}= \begin{cases}1 & t>B P \\
0 & \text { otherwise }\end{cases} \\
\qquad \mathrm{DT}_{\mathrm{t}}= \begin{cases}t & t>B P \\
0 & \text { otherwise }\end{cases}
\end{aligned}
$$

For the sample size, $T$, an OLS regression is implemented with a potential break-point at SB with the ranges from 2 to T-2. Similar to ADF and PP unit root tests, the maximum lag length, $L_{\max }$, is added to avoid the spurious serial correlation in the error terms with 12 extra lag regressors as indicated by Campbell and Perron $^{[20]}$. The lag coefficient is omitted stepwise with the last lag of the first differences is significant at $10 \%$ level. This test concludes the presence of random walk if the coefficient, $\delta$, is not significantly different from zero. Whereas, if the coefficient is less than zero, then it implied that the time series is mean-reverted. The test statistics of $\delta$ are based on null hypothesis with not significantly different from zero and the decision can base on the student-t test. 


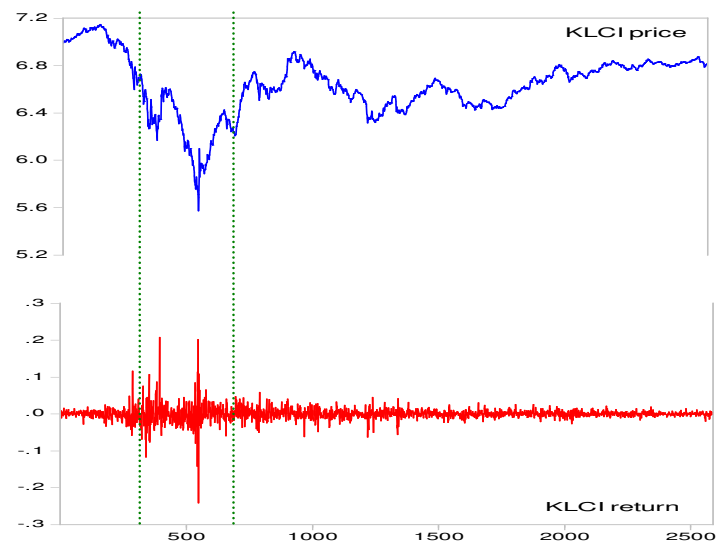

Fig. 1: Price and return series for KLCI

Table 1: Andrews break-point identification

\begin{tabular}{lccc}
\hline Index & Break point & LR SupF-stat & p-value \\
\hline KLCI & $9 / 1 / 1998$ & 23.9950 & $0.000^{\mathrm{c}}$ \\
INP & $9 / 1 / 1998$ & 20.0535 & $0.002^{\mathrm{c}}$ \\
IND & $9 / 1 / 1998$ & 22.4163 & $0.001^{\mathrm{c}}$ \\
COP & $9 / 1 / 1998$ & 23.8056 & $0.000^{\mathrm{c}}$ \\
CON & $9 / 1 / 1998$ & 20.4601 & $0.002^{\mathrm{c}}$ \\
MIN & $9 / 1 / 1998$ & 10.4428 & $0.079^{\mathrm{a}}$ \\
PRO & $12 / 24 / 1997$ & 16.0544 & $0.011^{\mathrm{b}}$ \\
PLA & $9 / 1 / 1998$ & 14.3136 & $0.024^{\mathrm{b}}$ \\
FIN & $8 / 17 / 1998$ & 21.8397 & $0.001^{\mathrm{c}}$ \\
TRA & & 7.9757 & 0.303 \\
\hline
\end{tabular}

Asymptotic distributions p-values are based on Hansen;

$\mathrm{a}, \mathrm{b}$ and $\mathrm{c}$ denote $10 \%, 5 \%$ and $1 \%$ level of significance.

\section{RESULTS AND DISCUSSIONS}

Break point identification: Figure 1 illustrated the plots of natural log price and return series for KLCI. Great potential of structural change is expected to observe in the price index with the relatively more volatile returns in the region between the green lines. Similarly, all the other indices indicated almost similar structural change within the year of 1997 to 1998. Other than that, the movements of the prices indices seem to be stable out the this region. Table 1 summarized the results of Quandt-Andrews test with the exact location of the break date due to the Asian financial crisis or currency control, Except the trading \& service index, significant break points are found for all the other indices. The earliest break is experienced by the Property index (12/24/1997) during the crisis, follows by Finance $(8 / 17 / 1998)$ and simultaneously by other indices at 9/1/1998, after the Malaysian government imposed the currency policy. Most of the indices rebounded significantly after the currency controls, for example, the KLCI radically increase by
$12 \%$, construction $13 \%$, finance, plantation, industrial product, $9 \%$ and the lowest is $3 \%$ by property.

Unit root test with and without structural break: In Table 2, the unit root test without breaks are based on the augmented Dickey Fuller (ADF) and Phillip Perron (PP) approaches. For both the tests with or without the inclusion of trend, only one index namely the Trading \& Service rejected the random walk process at $5 \%$ significance level. Overall, 8 out of 9 sectoral indices tended to suggest the evidence of random walk process instead of mean reverting process. The supportive of random walk hypothesis may due to the mis-specification of the possible observed structural change during the crisis in year 1997 and 1998.

After the break-point identification, we tested the random walk hypothesis under the structural change. Table 3 shown that the dummy variables for shift $\left(\theta_{1}\right)$ and trend $\left(\theta_{3}\right)$ are all significantly differenced from zero at $5 \%$ level. It is necessary to point out that the trend of sudden changes in most of the indices are rather small with values $\times 10^{-05}$. However the exception is observed in Trading \& Service index where neither structural change is observed in intercept and trend. This result is consistent with the previous break-point identification analysis. According to the asymptotic critical values, we can reject the null hypothesis of random walk at $1 \%$ significance level for Construction, Mining, Finance and Trading \& Services indices. On the other hand, KLCI, Industrial Product, Industrial, Consumer Product and Plantation can be rejected at 5\% significance level respectively. Exception is viewed for Property index where the crisis shock is permanent and there is no tendency for the Property price level to return to a trend path. As the conclusion, the broad examination indicated most of the sectoral indices may be well-followed mean reverting processes.

\section{CONCLUSION}

This paper studied whether the Malaysian stock markets follow a random walk or mean reverting processes under the structural break. Our results demonstrate that Asian Crisis and currency control show instantaneous impacts to the Malaysian stock market in general. For all sectoral indices we found a significant structural change during the Asian crisis (Property and Finance), after the currency control (Industrial Product, Consumer Product, Construction, Mining and Plantation) and exceptional for Trading \& Service index. 
Am. J. Applied Sci., 5 (10): 1291-1295, 2008

Table 2: Unit root tests without structural change

\begin{tabular}{|c|c|c|c|c|c|c|c|c|c|}
\hline & \multicolumn{4}{|c|}{$\mathrm{ADF}$} & \multicolumn{4}{|c|}{ PP } & \multirow[b]{2}{*}{ lag } \\
\hline & no trend & p-value & trend & p-value & no trend & $\mathrm{p}$-value & trend & $\mathrm{p}$-value & \\
\hline 1 & -2.072 & 0.256 & -2.215 & 0.480 & -2.058 & 0.262 & -2.190 & 0.495 & 5 \\
\hline 2 & -2.546 & 0.105 & -2.180 & 0.500 & -2.502 & 0.115 & -2.142 & 0.521 & 6 \\
\hline 3 & -1.540 & 0.513 & -2.066 & 0.564 & -1.540 & 0.513 & -2.066 & 0.564 & 0 \\
\hline 4 & -1.449 & 0.559 & -2.048 & 0.574 & -1.434 & 0.567 & -2.018 & 0.591 & 1 \\
\hline 5 & -2.286 & 0.177 & -2.132 & 0.527 & -2.232 & 0.195 & -2.100 & 0.545 & 6 \\
\hline 6 & -2.395 & 0.143 & -2.464 & 0.346 & -2.395 & 0.143 & -2.464 & 0.346 & 0 \\
\hline 7 & -2.262 & 0.185 & -2.011 & 0.594 & -2.248 & 0.189 & -2.005 & 0.598 & 2 \\
\hline 8 & -1.328 & 0.619 & -1.715 & 0.745 & -1.340 & 0.613 & -1.712 & 0.746 & 5 \\
\hline 9 & -1.787 & 0.388 & -2.046 & 0.575 & -1.775 & 0.393 & -2.021 & 0.589 & 4 \\
\hline 10 & -2.928 & $0.042 *$ & -4.141 & $0.006^{*}$ & -2.869 & $0.049^{*}$ & -4.037 & $0.008^{*}$ & 1 \\
\hline
\end{tabular}

1. Both the null hypothesis follows: $\mathrm{H}_{0}$ : The series has a unit root.

2. The maximum lag length is set to 12 and truncated with lag 12 for ADF test and PP test respectively as proposed by Campbell and Perron

3. $\tau_{\text {critical }}$ for intercept only are $-3.43,-2.86$ and -2.56 for $1 \%, 5 \%$ and $10 \%$ based on MacKinnon (1996);

4. $\tau_{\text {critical }}$ for intercept and trend are $-3.96,-3.41$ and -3.13 for $1 \%, 5 \%$ and $10 \%$ based on MacKinnon (1996);

5 . * denotes $5 \%$ significance level.

Table 3: Random walk with structural change

\begin{tabular}{|c|c|c|c|c|c|c|c|}
\hline & & p-value & $\theta_{3}$ & p-value & $\delta$ & $\mathrm{p}$-value & lag \\
\hline KLCI & -0.0095 & $0.013^{\mathrm{b}}$ & $-3.94 \times 10^{-05}$ & $0.001^{\mathrm{c}}$ & -0.0098 & $0.012^{\mathrm{b}}$ & 6 \\
\hline INP & -0.0102 & $0.020^{\mathrm{b}}$ & $3.82 \times 10^{-05}$ & $0.001^{\mathrm{c}}$ & -0.0091 & $0.012^{\mathrm{b}}$ & 6 \\
\hline IND & -0.0113 & $0.012^{b}$ & $4.08 \times 10^{-05}$ & $0.001^{\mathrm{c}}$ & -0.0099 & $0.012^{\mathrm{b}}$ & 6 \\
\hline $\mathrm{COP}$ & -0.0102 & $0.010^{\mathrm{b}}$ & $3.39 \times 10^{-05}$ & $0.000^{c}$ & -0.0095 & $0.014^{\mathrm{b}}$ & 1 \\
\hline $\mathrm{CON}$ & -0.0142 & $0.005^{\mathrm{c}}$ & $5.93 \times 10^{-05}$ & $0.000^{c}$ & -0.0106 & $0.007^{\mathrm{c}}$ & 6 \\
\hline MIN & -0.0199 & $0.002^{c}$ & $6.42 \times 10^{-05}$ & $0.000^{\mathrm{c}}$ & -0.0123 & $0.002^{c}$ & 5 \\
\hline PRO & -0.0080 & $0.021^{\mathrm{b}}$ & $4.58 \times 10^{-05}$ & $0.000^{c}$ & -0.0029 & 0.231 & 6 \\
\hline PLA & -0.0064 & $0.011^{\mathrm{b}}$ & $2.07 \times 10^{-05}$ & $0.000^{\mathrm{c}}$ & -0.0049 & $0.027^{\mathrm{b}}$ & 5 \\
\hline FIN & -0.0094 & $0.003^{c}$ & $4.31 \times 10^{-05}$ & $0.000^{\mathrm{c}}$ & -0.0075 & $0.002^{\mathrm{c}}$ & 6 \\
\hline TRA & -0.0002 & 0.852 & $-1.48 \times 10^{-06}$ & 0.657 & -0.0070 & $0.000^{\mathrm{c}}$ & 12 \\
\hline
\end{tabular}

1. Model: $\Delta p_{t}=\theta_{0}+\theta_{1} D M_{t}+\theta_{2} t+\theta_{3} D T_{t}+\delta p_{t-1}+\sum_{i=1}^{L} \pi_{i} \Delta p_{t-n}+\varepsilon_{t}$

2. The maximum lag length is set to 12 as proposed by Campbell and Perron (1991);

3. $\mathrm{b}$ and $\mathrm{c}$ denote $5 \%$ and $1 \%$ level of significance.

The empirical evidence the presence of mean reverting processes in almost all the sectoral market which implied the tendency for price level return to its initial trend path which provided the useful information in future forecasting. In addition, these finding also implied that most of the sectoral stock markets are weak-form inefficient. Only the Property market indicated the shock element is permanent with no predictable component in the historical observations.

\section{ACKNOWLEDGEMENT}

The author would like to gratefully acknowledge financial support from Multimedia University.

\section{REFERENCES}

1. Bachelier, L.,1900. Theory of speculation, in Cootner, P.(ed), Te random character of stock market prices, MIT Press, Cambridge, MA, 1964; Reprint.

2. Samuelson, P., 1965. Proof that properly anticipated prices fluctuate randomly, Industrial Management Review, 6, 41-49.

3. Fama, E., 1970. Efficient capital markets: a review of theory an empirical work, Journal of Finance, 25, 269-282.

4. Bai, J and Perron, P., 1998. Estimating and testing linear models with multiple structural changes, Econometrica, 66, 47-78. 
5. Chaudhuri, K., and Wu, Y., 2003. Random walk versus breaking trend in stock prices: evidence from emerging markets, Journal of Banking and Finance, 27, 575-592.

6. Henry, P.B., 2000. Stock market liberalization, economic reform and emerging market equity price, Journal of Finance, 55, 529-564.

7. Chin W.C. and I. Zaidi, 2007. The impact of multiple structural-breaks on Malaysian Stock Market, E. J of. Econ. Fin. and Ad. Sc., 7: 94-103.

8. Goh K.L., Y.C. Wong and Kok K.L., 2005. Financial crisis and intertemporal linkages across the ASEAN-5 sto ck markets, Review of Quantitative Finance and Accounting, 24: 359-377.

9. Kok, K.L. and F.F. Lee, 1994. Malaysian second board stock market and the efficient market hypothesis, Malaysian Journal of Economic Studies, 31(2): 1-13.

10. Lim, K.P., M.S. Habibullah and H.A. Lee, 2003. A BDS test of random walk in the Malaysian stock market. Labuan Bulletin of International Business and Finance, 1(1), 29-39.

11. Zivot, E., Andrews, D.W.K., 1992. Further evidence on the great crush, the oil price shock and the unit root hypothesis, Journal of Business and Economic Statistics, 10, 251-270.

12. Andrews, D.W.K., 1993. Tests for parameter instability and structural change with unknown change point, Econometrica, 61, 821-856.

13. Quandt, R. (1960). Tests of the hypothesis that a linear regression system obeys tow separate regimes, Journal of the American Statistical Association, 55, 324-330.
14. White, H., 1980. A heteroskedasticity-consistent covariance matrix and a direct test for heteroskedasticity, Econometrica, 48, 817-838.

15. Hansen, B.E., 1995. Approximate asymptotic pvalues for structural change test, Boston College Working Papers in Economics 297, Boston College.

16. Dickey, D.A., Fuller, W., 1981. Likelihood ratio statistics for autoregressive time series with a unit root, Econometrica, 49: 1057-1082.

17. Phillips P.C.B. and P. Perron, 1988). Testing for a unit root in time series regression, Biometrika, 75, 335-346.

18. Perron, P., 1989. The great crush, the oil price shock and the unit root hypothesis, Econometrica, 55,277-302.

19. Vogelsang T.J. and P. Perron, 1998. Additional tests for a unit root allowing for a break in the trend function at an unknown time, International Economic Review, 39, 1073-1100.

20. Campbell J.Y. and P. Perron, 1991. Pitfalls and opportunities: What macroeconomists should know about unit roots, NBER. In: Macroeconomics Annual, MIT Press, Cambridge, MA, 141-201. 